\title{
Economic Evaluations on Antimicrobial Stewardship Programme: A Systematic Review
}

Nor Haizan Ibrahim ${ }^{1}$, Khalidah Maruan ${ }^{1}$, Hasryn Azzuar Mohd Khairy ${ }^{1}$, Yet Hoi Hong ${ }^{2}$, Ahmad Fauzi Dali ${ }^{1}$, Chin Fen $\mathrm{Neoh}^{1,3}$

${ }^{1}$ Department of Pharmacy Practice, Faculty of Pharmacy, Universiti Teknologi MARA (UiTM), 42300 Bandar Puncak Alam, Selangor Darul Ehsan, Malaysia. ${ }^{2}$ Department of Physiology, Faculty of Medicine, University of Malaya, Kuala Lumpur, Malaysia. ${ }^{3}$ Collaborative Drug Discovery Research (CDDR) Group, Pharmaceutical and Life Sciences Community of Research, UiTM, Selangor Darul Ehsan, Malaysia.

Received, October 22, 2017; Revised, November 6, 2017; Accepted, November 7, 2017; Published, November 7, 2017.

ABSTRACT - Purpose: To systematically review studies on cost-effectiveness of implementing Antimicrobial stewardship programmes (ASP) in the hospital setting. Methods: A systematic literature search was performed using electronic databases, such as EMBASE, PubMed/Medline, CINAHL, NHS and CEA Registry from 2000 until 2017. The quality of each included study was assessed using Joanna Briggs Institute Critical Appraisal Checklist for Economic Evaluations and Consolidated Health Economic Evaluation Reporting Standards Statement checklist. Results: Of the 313 papers retrieved, five papers were included in this review after assessment for eligibility. The majority of the studies were cost-effectiveness studies, comparing ASP to standard care. Four included economic studies were conducted from the provider (hospital) perspective while the other study was from payer (National Health System) perspective. The cost included for economic analysis were as following: personnel costs, warded cost, medical costs, procedure costs and other costs. Conclusions: All studies were generally well-conducted with relatively good quality of reporting. Implementing ASP in the hospital setting may be cost-effective. However, comprehensive cost-effectiveness data for ASP remain relatively scant, underlining the need for more prospective clinical and epidemiological studies to incorporate robust economic analyses into clinical decisions.

This article is open to POST-PUBLICATION REVIEW. Registered readers (see "For Readers") may comment by clicking on ABSTRACT on the issue's contents page.

\section{INTRODUCTION}

Antimicrobial resistance is a growing public health threat. It has been associated with high mortality, with more than one million people die from drugresistant infections over the last two years [1]. Managing antimicrobial resistance is a costly exercise; in the United States alone, an excess cost of 20 billion USD was spent to treat these drug-resistant infections annually [2]. Resistance to new superbugs has reached an alarming level and more importantly, no major new types of antibiotics have been developed in the past three decades [3]. This looming public health threat has attracted the attention of various governments and global organisations, and thus, numerous strategies, including antimicrobial stewardship programmes (ASP), have been deliberated to combat antimicrobial resistance.

ASP aims to improve antimicrobial use (i.e. optimal selection, dosage, and duration of antimicrobial treatment) to optimise clinical outcomes and patient safety, reduce resistant infections, and minimise costs [4]. Two core strategies, which involves (1) prospective audit with intervention and feedback, and (2) formulary restriction and pre-authorisation, are identified as the foundation of ASP [4]. Davey et al. classified the antimicrobial stewardship intervention types into three: persuasive (e.g. audit, educational programmes, reminders, feedback), restrictive (e.g. formulary restrictions, authorisation, antibiotic cycling) and structural (e.g. computerisation of records, decision support system) [5]. Numerous studies [6-8] have shown the effectiveness of ASP and its interventions; and recently, there is an

Corresponding Author: Chin Fen Neoh, Department of Pharmacy Practice, Faculty of Pharmacy, Universiti Teknologi MARA (UiTM), 42300 Bandar Puncak Alam, Selangor Darul Ehsan, Malaysia, E-mail: neohchinfen@puncakalam.uitm.edu.my 
increasing emphasis in evaluating cost-effectiveness upon implementation of these interventions. The recent reviews involved a large variation in the method and depth of ASP being economically evaluated (i.e. included predominantly costing studies [9], focused mainly on the clinical outcomes [10] or a narrative review with only one database was search [11]). The studies, therefore, were limited by substantial inter-study methodological heterogeneity, hindering meaningful conclusion to be drawn. Partial economic evaluations that took only drug acquisition cost of antimicrobial agents into consideration would have underestimated cost advantage and health benefit of ASP. Accordingly, the aim of the current study was to systematically review the economic evaluations of ASP in the hospital setting, facilitating informed decision making by policy makers and healthcare providers, in particular the countries with budget constraint.

\section{METHODS}

\section{Search Strategy}

A systematic search of electronic databases, including EMBASE, PubMed/Medline, CINAHL, NHS and CEA Registry website from year 2000 to 2017, was performed by two independent authors (KM and NHI). The combinations of search terms, together with MESH terms, employed in this review were as follow: "(Antimicrobial OR antibiotic) AND stewardship AND (economics OR cost). These included (("'anti-bacterial agents"'"[Pharmacological Action] OR "'antibacterial agents"'"[MeSH Terms] OR ("'antibacterial""'[All Fields] AND ""agents"'"[All Fields]) OR "'anti-bacterial agents"'"[All Fields] OR "'"antibiotics"'"[All Fields]) AND "'cost""'[All Fields] OR "'costs and cost analysis"'"[MeSH Terms] OR ("'costs"'"[All Fields] AND "'cost""[All Fields] AND ""analysis""'[All Fields]) OR "'costs and cost analysis"'"[All Fields])) AND stewardship [All Fields]. The final search was done in October 2017.

\section{Study Selection}

Economic evaluations [i.e. cost-effectiveness analysis (CEA), cost-utility analysis or cost-benefit analysis] of ASP were included in this systematic review. The exclusion criteria were as follow: studies that included only direct cost of antimicrobial agents, studies presented only as abstracts with no full reporting of findings, review papers, editorial letter,
non-English literatures, studies involving ASP in the outpatient setting, studies comparing the effectiveness of different antibiotic regimens and studies before year 2000 were all excluded. Partial economic evaluations were excluded due to the fact that the lack of information for performing an indepth quality assessment while studies before year 2000 were excluded due to the rapid advancement in ASP. The eligibility of all potential economic studies identified for inclusion was independently assessed by two review authors (KH and NHI). Any discrepancies on study inclusion were resolved through discussion and consensus.

\section{Data Extraction and Collection}

A standardised, electronic form was used to extract data from each economic study. Data (e.g. country, type of economic analysis, year of costing, perspective, time horizon, comparators, cost components, outcome measure, sensitivity analysis, economic findings) obtained from the included studies were independently extracted by two authors (KH and NHI).

\section{Assessment of Methodological Quality}

Quality assessment for all included economic studies were independently assessed (KM and $\mathrm{NHI}$ ) using criteria as outlined in the Joanna Briggs Institute Critical Appraisal Checklist for Economic Evaluations [12]. The quality of reporting was evaluated using the Consolidated Health Economic Evaluation Reporting Standards checklist [13]. Any disagreement was resolved by discussion between the authors.

\section{RESULTS}

\section{Description of Included Studies}

A total of 313 studies was identified via the search. After removal of duplicates ( $n=34), 244$ studies were excluded based on the pre-specified criteria (Figure 1). A total of five economic studies investigating the cost-effectiveness of ASP in the hospital setting were included in the qualitative synthesis. Four studies were published within the past five years and were from Western countries. All studies were carried out in the different settings of hospital, with two studies conducted in both general and critical care units [14, 15], one study in critical care unit only [16], one in urology ward [17] and one in surgical and nonsurgical wards and emergency department [18]. 


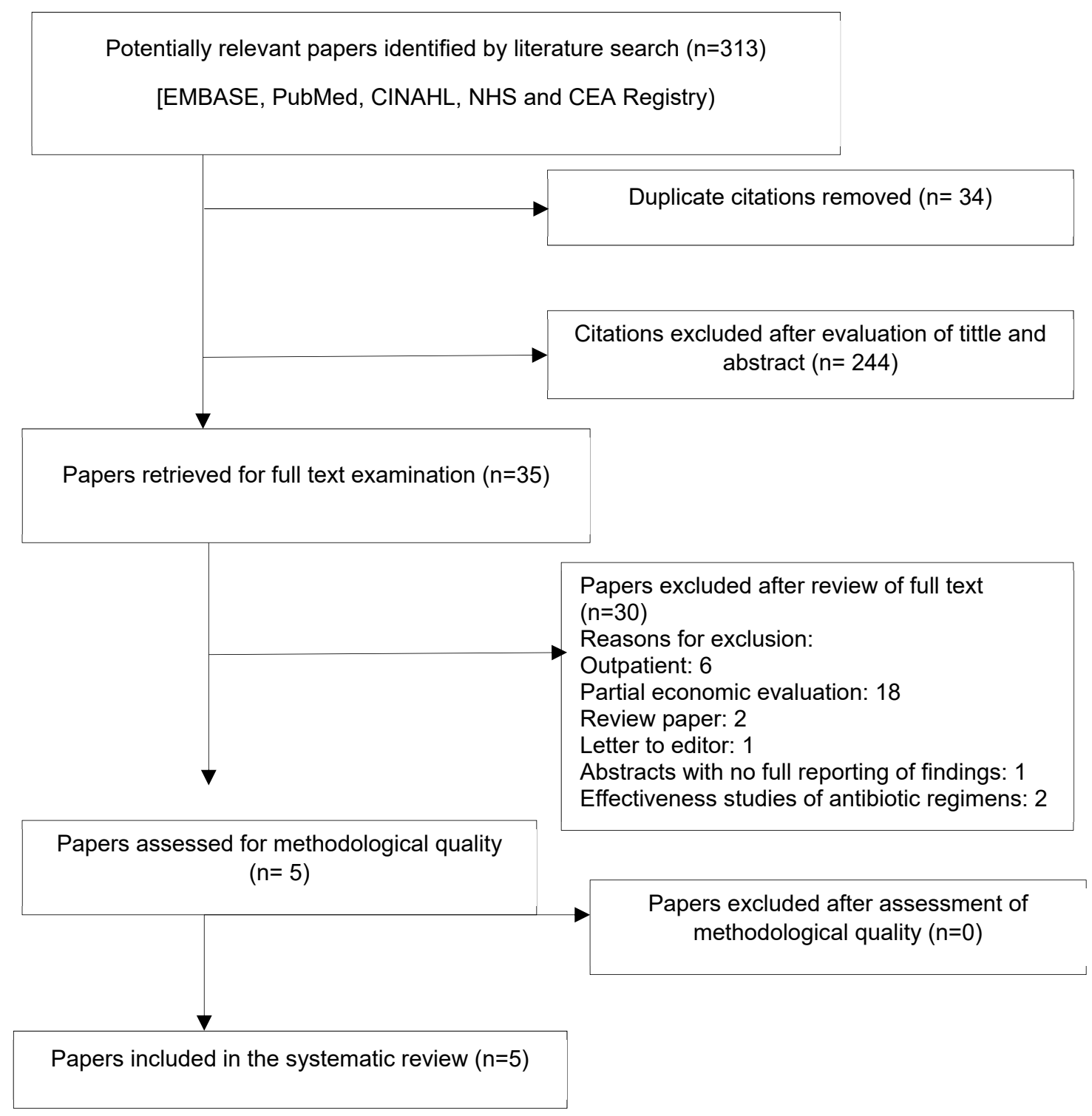

Figure 1. Flow chart of the search method

All included papers were CEA [14-16, 18], except one was cost-benefit analysis [17] (Table 1). The majority of them were conducted from provider (hospital) perspective $[14,15,17,18]$ with only one study was from a payer (i.e. National Health System) perspective [16]. Hence, only direct medical costs were taken into account, which comprised of hospitalisation, healthcare providers and drug costs. Apart from that, additional cost such as computerised clinical decision support system was included in the study by Scheetz et al. [14] while Okumura et al. included research cost in the analysis
[15]. Development costs of antibiotic checklist, implementation costs (i.e. web site, e-learning, briefing, posters and laminated pocket version) and operational costs were included in the study by Van Daalen et al. [18]. All costs were obtained retrospectively in all studies except one study [16] obtained the average cost from the published literature.

Four studies compared ASP to standard care [14, 16-18] while the other study compared the two different types of ASP strategies (i.e. bundled ASP versus conventional strategy) [15]. In the study by 
Okumura et al. [15], bundle ASP consisted of prospective auditing and local education about prescription of antibiotics therapy, microbiological data discussion with laboratory personnel to guide empirical or pre-emptive treatment and face-to-face interventions to enhance antimicrobial drug therapy. On the other hand, conventional ASP strategy included a clinical pharmacist screening for antimicrobial drug-related problem, case discussions with infectious disease physicians and telephonebased interventions [15]. Wide variation in the type and depth of ASP intervention(s) was noted in the other four studies that compared ASP to standard care. For instance, Scheetz et al. [14] evaluated Antibiotic Stewardship Team (A-ST) that included expert opinion decision for active treatment of BSI and implementing a computerised clinical decision support system in their strategies (i.e. structural intervention) while Dik et al. [17] applied day-2 case audit after initiation of antimicrobial therapy (i.e. persuasive intervention). Van Daalen et al. [18] developed and implemented the use of antibiotic checklist (i.e. persuasive intervention) in nine Dutch hospitals and evaluated the cost-effectiveness of checklist usage as ASP intervention. Antimicrobial stewardship interventions in the study by RuizRamos et al. [16] was comprehensive, which included antimicrobial restriction (both antibiotics and antifungals), formal consultation, implementation of protocols for de-escalation and guidelines for antibiotic prophylaxis or treatment, formal reassessment of antimicrobials and implementation of computer-assisted decision support (i.e. persuasive, restrictive and structural interventions).

Several modelling techniques were reported across the four included studies, including decision tree $[14,16]$, a 30-day Markov model [15] and costminimisation model [17]. Van Daalen et al. study [18] did not adopt any modelling techniques. Four studies employed incremental cost-effectiveness ratio (ICER) as model outcome [14-16, 18], except one used return on investment [17]. All included studies, except one [18], conducted both deterministic and probabilistic sensitivity analyses to compute the effect of uncertainty in input variables on model outcome. Only one study ran the subgroup analysis since the cohort were from two different groups of patients (i.e. one had infection-related indications and the other had severe underlying diseases such as cancer) [17]. All studies concluded that ASP was cost-effective in either short- or longterm setting.

\section{Quality Assessment}

The quality assessment and quality of reporting of the five studies were summarised in the Table 2 and Table 3, respectively. In general, most studies were able to adequately report at least 16 items that essential for performing an economic evaluation, indicating that these studies were of good quality of methodology.

\section{DISCUSSION}

Whilst the five economic evaluations included in the current review suggested that implementation of ASP was a cost-effective option in the hospital setting, these findings need to be interpreted with caution. The lack of standardisation in outcome measure of the economic evaluations in the ASP setting, in addition to the inconsistencies in the study design and depth of the ASP interventions employed, has hindered the usefulness of data on costs and benefits in the current evidence-based practice. It is important to note that there is a wide variation in the outcome measure reported among the economic studies in the current review [e.g. ICER per life-years gained, ICER per quality-adjusted life years (QALYs) gained or ICER per averted death in 30 days)]. In addition, return on investment was reported as an outcome measure in one of the studies [17]. Return on investment is a form of cost-benefit analysis that measures the cost of program versus the financial return from that programme, calculated as total benefit minus total cost (net benefit) over total cost [19]; the benefits of intervention are converted into monetary [20]. However, a return on investment analysis typically relies on short-term returns and often ignores the health of beneficiaries or patients [20]. Future studies should consider QALY, which takes into account the quality of life of those who experience the health outcomes, as a standardised outcome measure (effectiveness) [16] since it permits comparability across the economic analyses. The outcome probabilities (i.e. input variables for effectiveness data) for all included studies were mainly obtained from the published literatures [14, 16] or historical cohort studies $[15,17,18]$. These retrospective data could be subject to bias due to incomplete record and loss of follow up. Furthermore, estimation of the levels and long-term effects of antimicrobial resistance that will have on 
patient evolution as well as disease transmission are not being taken into consideration in these economic studies, and thus, underestimating the impact of ASP. All studies attained the cost inputs retrospectively and through gross costing except the study by Ruiz-Ramos et al. used average cost from published literatures in other countries to estimate antimicrobial cost per patient in critical care unit [16]; the appropriateness of adopting cost data from other countries into the analysis is a major consideration.

The included economic studies had high level of heterogeneity due to differences in the study setting, ASP strategies, clinical benefits and economic measurements. Therefore, it is difficult to determine which type of ASP strategies is the most costeffective. This is further complicated by the dearth of economic evaluations in determining the costeffectiveness of ASPs. The ASP interventions implemented in the economic studies included in the current review fulfilled most of the core elements of hospital ASP requirements set by Centers for Disease Control and Prevention, which includes leadership commitment, accountability, drug expertise, action, tracking, reporting and education [21]. Whilst multiple approaches in ASP interventions (i.e. bundled ASP strategy) are expected to provide better health outcomes, however, the driver of the cost-effectiveness cannot be distinguished and determined. Of note, none of these economic evaluations was conducted from societal perspective. Most economic studies were conducted from institutional (i.e. payer and provider) perspective given that the funding of ASP comes from the hospital administration; the societal benefits of ASP (e.g. loss of productivity due to multidrug resistant infections), however, should not be underestimated [14].

The difficulty in directly extrapolating the published economic findings to the appropriate patient populations that reflect the clinical caseload encountered in daily practice remains to be resolved since the economic studies included in the current review were conducted in critical care, urology wards, surgical and non-surgical wards and emergency department. Apart from that, other factors such as variability in healthcare systems and the resistance pattern which may differ according to the geographical areas pose great challenges to transfer cost-effectiveness data between countries.
The current review emphasises the need for research on a more systematic approach to evaluate the cost-effectiveness of individual ASP programmes. Robust health economic evaluations will provide a reasonable foundation for decisionmaking and thus, facilitating the ideal allocation for limited resources countries to fight against antimicrobial resistance. In general, the quality and execution of the included economic studies on economic evaluation were considered satisfactory. In the current review, the Joanna Briggs Institute Checklist for Economic Evaluation [12] was used to appraise the economic studies in addition to the Consolidated Health Economic Evaluation Reporting Standards checklist [13]. A 'YES' on the Consolidated Health Economic Evaluation Reporting Standards checklist may not adequately assess the quality of the criteria, but may only to indicate the completeness of the reporting rather than whether the choices were appropriate or justified. The present work, however, has shortcomings. Only studies published in English were included, and thus, leading to the small numbers of retrieved articles. The high level of the methodological heterogeneity, in terms of ASP interventions, that was noted in the current review is another limitation.

\section{CONCLUSION}

Although implementing ASP in the hospital setting is considered to be cost-effective, existing economic evaluations are limited by their great variation in the study design, outcome measure, types of ASP intervention and clinical settings. Therefore, future research evaluating the economic impact of ASP should consider using a standardised outcome measure with a longer time horizon of analysis. Robust economic studies to assess the cost-effective component of ASP across an extended clinical setting are anticipated.

\section{TRANSPARENCY DECLARATIONS}

All authors have no conflicts of interest to declare. This review was partially supported by UiTM internal grant (600-IRMI/DANA5/3/BESTARI (044/2017). 


\begin{tabular}{|c|c|c|c|c|c|c|c|c|}
\hline Source & $\begin{array}{l}\text { Type of } \\
\text { analysis }\end{array}$ & $\begin{array}{l}\text { Currency, } \\
\text { year of } \\
\text { costing }\end{array}$ & $\begin{array}{l}\text { Perspective } \\
\text { (Timeframe) }\end{array}$ & Comparator & $\begin{array}{l}\text { Outcome } \\
\text { measure(s) }\end{array}$ & $\begin{array}{l}\text { Sensitivity Analysis (SA), } \\
\text { (variable inputs) }\end{array}$ & Economic Findings & Conclusion \\
\hline [14] & CEA & US\$, 1999 & $\begin{array}{l}\text { Provider- } \\
\text { Hospital } \\
\text { (Not stated) }\end{array}$ & $\begin{array}{l}\text { ASP versus } \\
\text { Standard care }\end{array}$ & ICER/QALY & $\begin{array}{l}\text { One-way SA (e.g. ability of } \\
\text { ASP to transit patient to active } \\
\text { treatment), multi-way SA and } \\
\text { probabilistic SA (e.g. event } \\
\text { likelihoods, } \\
\text { cost ranges, utility ranges) }\end{array}$ & $\begin{array}{l}\text { ICER was US } \$ 2,367 \text { per } \\
\text { QALY gained and more } \\
\text { than } 90 \% \text { likelihood that } \\
\text { ASP was cost effective at } \\
\text { level of US\$10,000 per } \\
\text { QALY }\end{array}$ & $\begin{array}{l}\text { Maintaining } \\
\text { ASP to } \\
\text { improve care } \\
\text { of } \\
\text { bacteraemia } \\
\text { is cost- } \\
\text { effective } \\
\text { from the } \\
\text { hospital } \\
\text { perspective }\end{array}$ \\
\hline [17] & $\begin{array}{l}\text { Cost- } \\
\text { benefit } \\
\text { analysis }\end{array}$ & $\begin{array}{l}\text { Euro } \\
€, 2013\end{array}$ & $\begin{array}{l}\text { Provider- } \\
\text { Hospital } \\
\text { (1 year) }\end{array}$ & $\begin{array}{l}\text { ASP versus } \\
\text { Standard care }\end{array}$ & $\begin{array}{l}\text { Return on } \\
\text { investment }\end{array}$ & $\begin{array}{l}\text { Multi-variate SA (e.g. LOS, \% } \\
\text { primary admitted due to } \\
\text { infection, cost for consultant, } \\
\text { expected LOS due to } \\
\text { antimicrobial resistance) and } \\
\text { probabilistic SA (e.g. LOS, } \\
\text { nursing time, antibiotic costs) }\end{array}$ & $\begin{array}{l}\text { The model estimated total } \\
\text { savings of } € 60,306 \text { after } \\
\text { one year for this single } \\
\text { department, leading to a } \\
\text { return on investment of } \\
5.9\end{array}$ & $\begin{array}{l}\text { The } \\
\text { implemented } \\
\text { multi-discipli } \\
\text { nary A-Team } \\
\text { performing a } \\
\text { day-2 case } \\
\text { audit in the } \\
\text { hospital had a } \\
\text { positive } \\
\text { return on } \\
\text { investment } \\
\text { caused by a } \\
\text { reduced LOS } \\
\text { due to a more } \\
\text { appropriate } \\
\text { antibiotic } \\
\text { therapy }\end{array}$ \\
\hline [15] & CEA & $\begin{array}{l}\text { Brazilian } \\
\text { Real and } \\
\text { converted } \\
\text { to US\$, } \\
2013\end{array}$ & $\begin{array}{l}\text { Provider- } \\
\text { Southern } \\
\text { Brazilian } \\
\text { University } \\
\text { Hospital } \\
\text { (30 days) }\end{array}$ & $\begin{array}{l}\text { Conventional } \\
\text { ASP strategy } \\
\text { versus Bundled } \\
\text { ASP strategy }\end{array}$ & $\begin{array}{l}\text { ICER/Averted } \\
\text { death in } 30 \text { days }\end{array}$ & $\begin{array}{l}\text { Deterministic SA (e.g. cost) } \\
\text { and probabilistic SA (e.g. } \\
\text { cost) }\end{array}$ & $\begin{array}{l}\text { Bundled ASP was } \\
\text { associated with an ICER } \\
\text { of US\$ } 19 \\
\text {,287.54 per averted death } \\
\text { in } 30 \text { days }\end{array}$ & $\begin{array}{l}\text { Bundled ASP } \\
\text { was more } \\
\text { cost-effective } \\
\text { and also } \\
\text { associated } \\
\text { with higher } \\
\text { probabilities } \\
\text { of clinical } \\
\text { success and at }\end{array}$ \\
\hline
\end{tabular}




\begin{tabular}{|c|c|c|c|c|c|c|c|c|}
\hline & & & & & & & & $\begin{array}{l}\text { reasonable } \\
\text { implementati } \\
\text { on costs }\end{array}$ \\
\hline [16] & CEA & $€, 2015$ & $\begin{array}{l}\text { Payer- } \\
\text { Spain } \\
\text { National } \\
\text { Health } \\
\text { System } \\
\text { (Not } \\
\text { reported) }\end{array}$ & $\begin{array}{l}\text { ASP versus } \\
\text { Standard care }\end{array}$ & ICER/LYG & $\begin{array}{l}\text { Univariate SA (e.g. reason for } \\
\text { admittance to critical care, } \\
\text { incidence of nosocomial } \\
\text { infection, reduction in } \\
\text { Clostridium difficile infection, } \\
\text { ASP impact on average } \\
\text { treatment cost) } \\
\text { and probabilistic SA (e.g. } \\
\text { short-term ASP benefit, } \\
\text { incidence of nosocomial } \\
\text { infection, percentage of multi- } \\
\text { resistant species present in the } \\
\text { unit, impact of ASP on the } \\
\text { prevalence of infection by } \\
\text { multi-resistant bacteria) }\end{array}$ & $\begin{array}{l}\text { ASP was associated with } \\
\text { an ICER of } 9,788 € / \text { LYG. } \\
\text { More than } 90 \% \text { likelihood } \\
\text { that an ASP would be } \\
\text { cost-effective at a level of } \\
8,000 € \text { per LYG. }\end{array}$ & $\begin{array}{l}\text { Implementing } \\
\text { an ASP } \\
\text { focusing on } \\
\text { critical care } \\
\text { patients is a } \\
\text { long-term } \\
\text { cost-effective } \\
\text { tool. }\end{array}$ \\
\hline [18] & CEA & $€, 2015$ & $\begin{array}{l}\text { Hospital } \\
\text { Perspective } \\
\text { (not reported) }\end{array}$ & $\begin{array}{l}\text { ASP versus } \\
\text { Usual care }\end{array}$ & $\begin{array}{l}\text { ICER/extra } \\
\text { patient } \\
\text { receiving } \\
\text { appropriate } \\
\text { treatment, and } \\
\text { ICER/day } \\
\text { reduction in } \\
\text { LOS }\end{array}$ & Not performed & $\begin{array}{l}\text { ICERs of } € 54.01 \\
\text { per extra patient with } \\
\text { appropriate treatment } \\
\text { and } \\
€ 51.43 \text { per day reduction } \\
\text { in LOS were reported. }\end{array}$ & $\begin{array}{l}\text { Implementati } \\
\text { on of this } \\
\text { antibiotic } \\
\text { checklist can } \\
\text { be a cost- } \\
\text { effective } \\
\text { antimicrobial } \\
\text { stewardship } \\
\text { strategy }\end{array}$ \\
\hline
\end{tabular}


J Pharm Pharm Sci (www.cspsCanada.org) 20, 397 - 406, 2017

\begin{tabular}{|c|c|c|c|c|c|c|}
\hline \multirow[t]{2}{*}{ ITEM } & \multirow[t]{2}{*}{ QUESTION } & \multicolumn{4}{|c|}{ STUDIES } & \multirow[b]{2}{*}{$\begin{array}{c}\text { Van Daalen et. } a l . \\
(2017)\end{array}$} \\
\hline & & $\begin{array}{l}\text { Sheetz et. al. } \\
\quad(2009)\end{array}$ & $\begin{array}{l}\text { Dik et. al. } \\
\text { (2015) }\end{array}$ & $\begin{array}{c}\text { Okumura et. al. } \\
\qquad(2016)\end{array}$ & $\begin{array}{l}\text { Ruiz-Ramos et. al. } \\
\text { (2017) }\end{array}$ & \\
\hline 1. & $\begin{array}{l}\text { Is there a well-defined } \\
\text { question/objective? }\end{array}$ & + & + & + & + & + \\
\hline 2. & $\begin{array}{l}\text { Is there comprehensive } \\
\text { description of alternatives? }\end{array}$ & + & + & + & - & + \\
\hline 3. & $\begin{array}{l}\text { Are all important and relevant } \\
\text { costs and outcomes for each } \\
\text { alternative identified? }\end{array}$ & + & + & + & Unclear & + \\
\hline 4. & $\begin{array}{l}\text { Has clinical effectiveness been } \\
\text { established? }\end{array}$ & + & Unclear & + & + & + \\
\hline 5. & $\begin{array}{l}\text { Are costs and outcomes } \\
\text { measured accurately? }\end{array}$ & + & + & + & + & + \\
\hline 6. & $\begin{array}{l}\text { Are costs and outcomes valued } \\
\text { credibly? }\end{array}$ & + & + & Unclear & + & + \\
\hline 7. & $\begin{array}{l}\text { Are costs and outcomes } \\
\text { adjusted for differential timing? }\end{array}$ & - & + & + & + & Unclear \\
\hline 8. & $\begin{array}{l}\text { Is there an incremental analysis } \\
\text { of costs and consequences? }\end{array}$ & + & - & + & + & + \\
\hline 9. & $\begin{array}{l}\text { Were sensitivity analyses } \\
\text { conducted to investigate } \\
\text { uncertainty in estimates of cost } \\
\text { or consequences? }\end{array}$ & + & + & + & + & - \\
\hline 10. & $\begin{array}{l}\text { Do study results include all } \\
\text { issues of concern to users? }\end{array}$ & Unclear & Unclear & + & + & + \\
\hline 11. & $\begin{array}{l}\text { Are the results generalizable to } \\
\text { the setting of interest in the } \\
\text { review? }\end{array}$ & Unclear & Unclear & + & + & + \\
\hline $\begin{array}{l}+=\text { Yes } \\
-=\text { No }\end{array}$ & & & & & & \\
\hline
\end{tabular}


Table 3. Consolidated Health Economic Evaluation Reporting Standard (CHEERS CHECKLIST)

\begin{tabular}{|c|c|c|c|c|c|}
\hline \multirow{2}{*}{ Section/Item } & \multicolumn{4}{|c|}{ Study } & \multirow[b]{2}{*}{$\begin{array}{c}\text { Van Daalen et. al. } \\
\text { (2017) }\end{array}$} \\
\hline & $\begin{array}{l}\text { Scheetz et. al. } \\
\quad(2009)\end{array}$ & $\begin{array}{l}\text { Dik et. al. } \\
\text { (2015) }\end{array}$ & $\begin{array}{l}\text { Okumura et. al. } \\
\qquad(2016)\end{array}$ & $\begin{array}{l}\text { Ruiz-Ramos et. al. } \\
\text { (2017) }\end{array}$ & \\
\hline \multicolumn{6}{|l|}{ Title/Abstract/Introduction } \\
\hline Title & A & A & A & A & A \\
\hline Abstract & A & A & A & A & A \\
\hline Background/objectives & A & A & A & $\mathrm{A}$ & A \\
\hline \multicolumn{6}{|l|}{ Methods } \\
\hline Target population/subgroups & A & A & A & A & A \\
\hline Setting/location & A & A & A & A & A \\
\hline Study perspective & A & A & A & A & A \\
\hline Comparators & A & A & A & A & A \\
\hline Time horizon & A & A & A & A & NA \\
\hline Discount rate & A & NA & A & A & NA \\
\hline Choice of health outcomes & A & A & A & A & A \\
\hline Measurement of effectiveness & A & A & A & A & A \\
\hline Estimating resources and costs & A & A & A & A & A \\
\hline Currency, price date, conversion & PA & A & A & PA & PA \\
\hline Choice of model & A & A & A & A & NA \\
\hline Assumptions & A & A & A & A & A \\
\hline Analytical model & A & A & A & A & NA \\
\hline \multicolumn{6}{|l|}{ Results } \\
\hline Study parameters & A & A & A & A & A \\
\hline Incremental costs and outcomes & A & NA & A & A & A \\
\hline Characterizing uncertainty & A & A & A & A & NA \\
\hline Characterizing heterogeneity & A & A & A & A & NA \\
\hline \multicolumn{6}{|l|}{ Discussion/Others } \\
\hline $\begin{array}{l}\text { Study findings, limitations, generalizability, current } \\
\text { knowledge }\end{array}$ & $\mathrm{A}$ & A & A & A & A \\
\hline Source of funding & A & A & A & A & A \\
\hline Conflict of interest & A & A & A & A & A \\
\hline $\begin{array}{l}\text { A - Adequate (Information was explicitly presented } \\
\text { PA - Partially adequate (Information was NOT expli } \\
\text { NA - Not adequate (No information about the matter }\end{array}$ & $\begin{array}{l}\text { ext) } \\
\text { esented but it } y \\
\text { ailable in the } t\end{array}$ & ggested) & & & \\
\hline
\end{tabular}




\section{REFERENCES}

1. O 'neill J. (2016). Tackling Drug-Resistant Infections Globally: Final Report and Recommendations. Retrieved from: https://amrreview.org

2. Smith R, Coast J. The true cost of antimicrobial resistance. British Medical Journal, 2013;346351:f1493. DOI: 10.1136/bmj.f1493

3. World Health Organisation. Antimicrobial resistance. Bulletin of the World Health Organization. 2014;61:383-394.

4. Dellit TH. Infectious Diseases Society of America and the Society for Healthcare Epidemiology of America Guidelines for Developing an Institutional Program to Enhance Antimicrobial Stewardship. Infectious Diseases in Clinical Practice. 2007;44:159-177. DOI: 10.1097/IPC.0b013e318068b1c0

5. Davey P, Ca M, Cl S, Charani E, McNeil K, Brown $\mathrm{E}$, et al. Interventions to improve antibiotic prescribing practices for hospital inpatients. The Cochrane database of systematic reviews. 2017:CD003543.

DOI:

10.1002/14651858.CD003543.pub4.

6. Dean NC, Bateman KA, Donnelly SM, Silver MP, Snow GL, Hale D. Improved clinical outcomes with utilization of a community-acquired pneumonia guideline. Chest Journal. 2006;130:794-799. DOI: 10.1378/chest.130.3.794

7. Perez KK, Olsen RJ, Musick WL, Cernoch PL, Davis JR, Peterson LE, et al. Integrating rapid diagnostics and antimicrobial stewardship improves outcomes in patients with antibiotic-resistant Gramnegative bacteremia. Journal of Infection. 2014;69:216-225.

DOI: http://dx.doi.org/10.1016/j.jinf.2014.05.005

8. Alawi MM, Darwesh BM. A stepwise introduction of a successful antimicrobial stewardship program: Experience from a tertiary care university hospital in Western, Saudi Arabia. Saudi Medical Journal. 2016;37:1350-1358. DOI:10.15537 / smj.2016.12 . 15739

9. Dik JWH, Vemer P, Friedrich AW, Hendrix R, LoTen-Foe JR, Sinha B, et al. Financial evaluations of antibiotic stewardship programs - a systematic review. Frontiers in Microbiology. 2015;6:317-332. DOI:10.3389/fmicb.2015.00317

10. Karanika S, Paudel S, Grigoras C, Kalbasi A, Mylonakis E. Clinical and Economic Outcomes from the Implementation of Hospital-based Antimicrobial Stewardship Programs: A Systematic Review and Meta-Analysis. Antimicrobial Agents and Chemotherapy. 2016;60(8):4840-4852. DOI: 10.1128/AAC.00825-16
11. Naylor NR, Zhu N, Hulscher M, Holmes A, Ahmad $\mathrm{R}$, Robotham JV. Is Antimicrobial Stewardship Cost-Effective? A Narrative Review of the Evidence. Clinical Microbiology and Infection. 2017; 23(11):806-811. DOI: 10.1016/j.cmi.2017.06.011.

12. The Joanna Briggs Institute. JBI Critical Appraisal tools for use in JBI Systematic Reviews: Checklist for Economic Evaluations., Australia, pp 1-6, 2016.

13. Husereau D, Drummond M, Petrou S, Carswell C, Moher D, Greenberg D. Consolidated Health Economic Evaluation Reporting Standards (CHEERS)--Explanation and elaboration: A report of the ISPOR Health Economic Evaluations Publication Guidelines Task Force. Value in Health. 2013;16:231-250.

DOI: http://dx.doi.org/10.1016/j.jval.2013.02.002

14. Scheetz MH, Bolon MK, Postelnick M, Noskin GA, Lee TA. Cost-effectiveness analysis of an antimicrobial stewardship team on bloodstream infections: A probabilistic analysis. Journal of Antimicrobial Chemotherapy. 2009;63:816-825. DOI: 10.1093/jac/dkp004Okumura LM, Riveros BS,

15. Gomes-da-Silva MM, Veroneze I. A costeffectiveness analysis of two different antimicrobial stewardship programs. The Brazilian Journal of Infectious Diseases. 2016;20:255-261. DOI: 10.1016/j.bjid.2016.02.005

16. Ruiz-Ramos J, Frasquet J, Romá E, Poveda-Andres JL, Salavert-Leti M, Castellanos A, et al. Costeffectiveness analysis of implementing an antimicrobial stewardship program in critical care units. Journal of Medical Economics. 2017;20(6):652-659.

DOI: 10.1080/13696998.2017Dik JWH, Hendrix R,

17. Friedrich AW, Luttjeboer J, Panday PN, Wilting KR, et al. Cost-minimization model of a multidisciplinary antibiotic stewardship team based on a successful implementation on a urology ward of an academic hospital. PLoS ONE Journal. 2015;10:6-13. DOI: https://doi.org/10.1371/journal.pone.0126106

18. van Daalen FV, Opmeer BC, Prins JM, Geerlings SE, Hulscher MEJL. The economic evaluation of an antibiotic checklist as antimicrobial stewardship intervention. Journal of Antimicrobial Chemotherapy. 2017;72(11):3213-3221. DOI: $10.1093 / \mathrm{jac} / \mathrm{dkx} 259$.

19. Goetzel RZ, Ph D, Ozminkowski RJ, et al. Return on Investment in Disease Management: A Review. Health Care Financ Rev. 2005;26:1-19.

20. Gramlich, E M. A Guide to Benefit-Cost Analysis. Englewood Cliffs, N.J. Prentice Hall, USA, 1991.

21. Pollack LA, Srinivasan A. Core Elements of Hospital Antibiotic Stewardship Programs From the Centers for Disease Control and Prevention.Clinical Infectious Disease. 2014;59(S3):S97-100. 